\title{
Discontinuity of Chronic Medications in Patients Discharged from the Intensive Care Unit
}

\author{
Chaim M. Bell, MD, PhD, FRCP(C), 1,2,3,4,5 Parisa Rahimi-Darabad, MD, ${ }^{1,2}$ Avi I. Orner, MD ${ }^{1}$ \\ ${ }^{1}$ Faculty of Medicine, University of Toronto, Toronto, ON, Canada; ${ }^{2}$ Department of Medicine, University of Toronto, Toronto, ON, Canada; \\ ${ }^{3}$ Department of Health Policy Management and Evaluation, University of Toronto, Toronto, ON, Canada; ${ }^{4}$ The Institute for Clinical \\ Evaluative Sciences, University of Toronto, Toronto, ON, Canada; '5epartment of Medicine, St. Michael's Hospital, Toronto, ON, Canada.
}

BACKGROUND: Intensive care unit (ICU) admission may connote an elevated risk of unintentional chronic medication discontinuation because of its focus on acute illnesses and the multiple care transitions.

OBJECTIVE: To determine the proportion of patients discharged from the ICU whose previously prescribed chronic medications were unintentionally discontinued during their hospitalization.

DESIGN AND PARTICIPANTS: Hospital records of consecutive ICU discharges at 1 academic and 2 community hospitals in Toronto, Canada, throughout 2002 were reviewed. Eligible patients were prescribed at least 1 of 6 medication groups before hospitalization: (1) HMG co-A reductase inhibitors (statins); (2) antiplatelets/anticoagulants (aspirin, clopidogrel, ticlopidine, warfarin); (3) L-thyroxine; (4) non-prn inhalers (anticholinergic, $\beta$-agonist, or steroid); (5) acid-suppressing drugs (H2 antagonists and proton pump inhibitors); and (6) allopurinol.

MEASUREMENTS: Use of explicit criteria to assess the proportion of patients whose previously prescribed chronic medications were unintentionally discontinued at hospital discharge.

RESULTS: A total of 1,402 charts were eligible for the study and 834 had prescriptions for at least 1 of the medication groups. Thirty-three percent $(251 / 834)$ of patients had 1 or more of their chronic medications omitted at hospital discharge. Multivariable logistic regression analysis found that patients from the academic hospital (adjusted odds ratio $[\mathrm{OR}]=0.70,95 \%$ confidence interval $[\mathrm{CI}] 0.49$ to 1.0 ) and those with medical diagnoses (adjusted $\mathrm{OR}=0.48,95 \% \mathrm{CI} 0.31$ to 0.75 ) had a decreased risk for chronic medication discontinuation.

CONCLUSIONS: Patients discharged from the ICU often leave the hospital without note of their previously prescribed chronic medications. Careful review of medication lists at ICU discharge could avoid potential adverse outcomes related to unintentional discontinuation of chronic medications at hospital discharge.

KEY WORDS: drug discontinuation; continuity of care; chronic medications; patient safety; intensive care unit.

DOI: $10.1111 / \mathrm{j} .1525-1497.2006 .00499 . x$

J GEN INTERN MED 2006; 21:937-941.

$\mathrm{L}$ ifelong medication adherence is essential for patients with chronic diseases to have continued risk reduction from important adverse outcomes. Unfortunately, many patients are not adherent to medications in the long term for a variety of reasons. Patient, physician, disease, and environment factors, as well as the interplay between them, all contribute to medication nonadherence. ${ }^{1-3}$ One cause for nonadherence is the unintentional discontinuation of medications that can occur during the

None of the authors have any conflicts of interest to declare.

Preliminary findings were presented in abstract form at the 29th Annual Meeting of the Society of General Internal Medicine in New Orleans in May 2005.

Address correspondence and requests for reprints to Dr. Bell: St. Michael's Hospital, 30 Bond Street, Toronto, ON, Canada M5B 1W8 (e-mail: bellc@smh.toronto.on.ca). particularly high-risk period of care transitions, when patient responsibility shifts from 1 physician to another. ${ }^{4-8}$

Long-term outcomes from chronic diseases are not usually the focus of care in the intensive care unit (ICU). Medications that treat chronic diseases are often held during the initial stages of the admission when the patient is being stabilized. ${ }^{9}$ These drugs may not be prescribed when recovering ICU patients are transferred to the hospital ward. In turn, patients may go without these important medications during the remainder of their hospitalization. This approach to care may place patients admitted to the ICU at higher risk for unintentional medication discontinuation following their hospital discharge. ${ }^{10-13}$

We studied patients prescribed any of 6 selected chronic medication groups before hospital admission who were discharged from the ICUs at 1 academic and 2 community institutions. Our aim was to determine the proportion of patients whose medications were unintentionally discontinued during their hospitalization and to identify possible predictive factors.

\section{METHODS}

Hospital records of consecutive ICU discharges at 1 academic and 2 community hospitals in Toronto, Canada, from January 1, 2002 to December 31, 2002 were reviewed. All ICUs are closed units and staffed by trained intensivists. Patients transferred from other medical facilities were excluded from the study. Emergency department records, ambulance reports, preadmission clinic documents, and hospital admission notes were reviewed for lists of medications prescribed before hospitalization. Eligible patients were prescribed at least 1 of 6 prespecified chronic medication groups: (1) HMG co-A reductase inhibitors (statins); (2) antiplatelets/anticoagulants (aspirin, clopidogrel, ticlopidine, warfarin); (3) L-thyroxine preparations; (4) non-prn inhalers (anticholinergic, $\beta$-agonist, or steroid); (5) acid-suppressing drugs (H2 antagonists and proton pump inhibitors); and (6) allopurinol. We chose these medication groups because of their established records of efficacy and evidence for long-term treatment. ${ }^{14-20}$ Also, they have few indications for intentional discontinuation. Therefore, failure to continue these chronic medications represents a potential adverse event and place patients at increased risk for adverse outcomes.

Hospital records were then examined for the prescription of the selected medications on discharge from the ICU and hospital based upon progress notes and physician orders. We developed explicit criteria based upon clinical documentation to determine whether medication discontinuation on ICU discharge was indicated or could have been intentional

Manuscript received October 24, 2005

Initial editorial decision December 14, 2005

Final acceptance March 15, 2006 
(Appendix 1). These criteria were devised through clinical discussions with experts and consultation with product monographs. Clinical context was considered so that specifically documented justification was not essential to determine deliberate medication discontinuation. For example, in a patient with a gastrointestinal hemorrhage, no documentation of the decision for aspirin discontinuation was required to ascertain the intent. Also, we specifically examined hospital records to determine intentional discontinuation of medications because of: (1) possible allergic reactions; (2) changes in goals of care to hospice; and (3) loss of enteral access.

Both reviewers had advanced medical training and clinical experience. Charts were usually reviewed by 1 person. We tested interrater agreement on 62 randomly selected patient charts. The proportion agreement was $87 \%$ and the $\kappa$ was 0.74 , indicating substantial agreement. ${ }^{21}$

Multivariate logistic regression was used to model the effect of predictors of unintentional discontinuation of any of the 6 drug classes at hospital discharge, and to adjust for the effect of confounding variables. The effects of exposures on the risk of drug discontinuation were expressed as odds ratios (ORs) and 95\% confidence intervals (CIs). We selected only those characteristics that we believed a priori were clinically implicated in the causal pathway for inclusion in the model. All reported $P$ values are 2-tailed. Analyses were performed with SAS Software Version 8.2 (Cary, NC).

Research ethics approval was obtained from all 3 hospitals involved in the study.

\section{RESULTS}

A total of 1,584 charts were reviewed and 1,402 were eligible for inclusion in the study (Fig. 1). In all, 74 patients died after discharge from the ICU but before hospital discharge. The demographic characteristics of the patients are summarized in Table 1.

The median age of the patients was 65 . About $43 \%$ were female. More than $95 \%$ of patients lived in the community. Most patients were admitted through the emergency department and about one-third were admitted directly to the ICU. Reasons for ICU admission were almost split equally between medical and surgical diagnoses. Patients were taking a median of 4 prescribed medications at hospital admission. Intubation was required in about one-third of patients. Patients spent a median 3 days in the ICU and 10 days in hospital.

In all, 834 patients were prescribed at least 1 of the 6 selected chronic medications. There were 307 (37\%) patients who had 1 or more of their chronic medications omitted on discharge from the ICU (Fig. 1). Of these 307 patients, 19 died before hospital discharge, 2 were transferred to palliative care facilities, and 91 people were prescribed their medications on discharge from hospital. There were 251 (33\%) patients of the 758 discharged home who had 1 or more of their chronic medications omitted. Of these 251 patients, 195 (78\%) had their medications discontinued on their discharge from ICU.

Patients discharged from teaching and community hospitals had similar proportions of medication discontinuation upon discharge from ICU (35\% vs 38\%, P>.2) and hospital (32\% vs $34 \%, P>.2$ ). Overall, about one-fifth of all patients initially prescribed L-thyroxine, antiplatelets/anticoagulants, and statins before hospital admission had their medications unintentionally discontinued at hospital discharge (Table 2).

\section{Adjusted Analyses}

The multivariable logistic regression analyses estimated the risk of drug discontinuation at hospital discharge in all 758 patients (Table 3). Only 2 characteristics demonstrated independent significance. Patients admitted to the academic ICU had a decreased risk of drug discontinuation (adjusted $\mathrm{OR}=0.70,95 \%$ CI 0.49 to 1.0 ). Patients admitted to the ICU with a medical diagnosis had a decreased risk of drug discontinuation (adjusted $\mathrm{OR}=0.48,95 \%$ CI 0.31 to 0.75). Age, sex, admission through the emergency department, having the same ward as ICU attending, patient intubation, number of prescribed medications on admission, and hospital and ICU length of stay had no significant effect. The analyses also demonstrated that patients who had their medication discontinued on ICU discharge had an OR of 17.2 (95\% CI 11.6 to 25.6) for having their medication discontinued on hospital discharge after adjusting for covariates.

\section{DISCUSSION}

We studied over 1,400 discharges from the ICUs at 1 academic and 2 community hospitals. We found that one-third left the

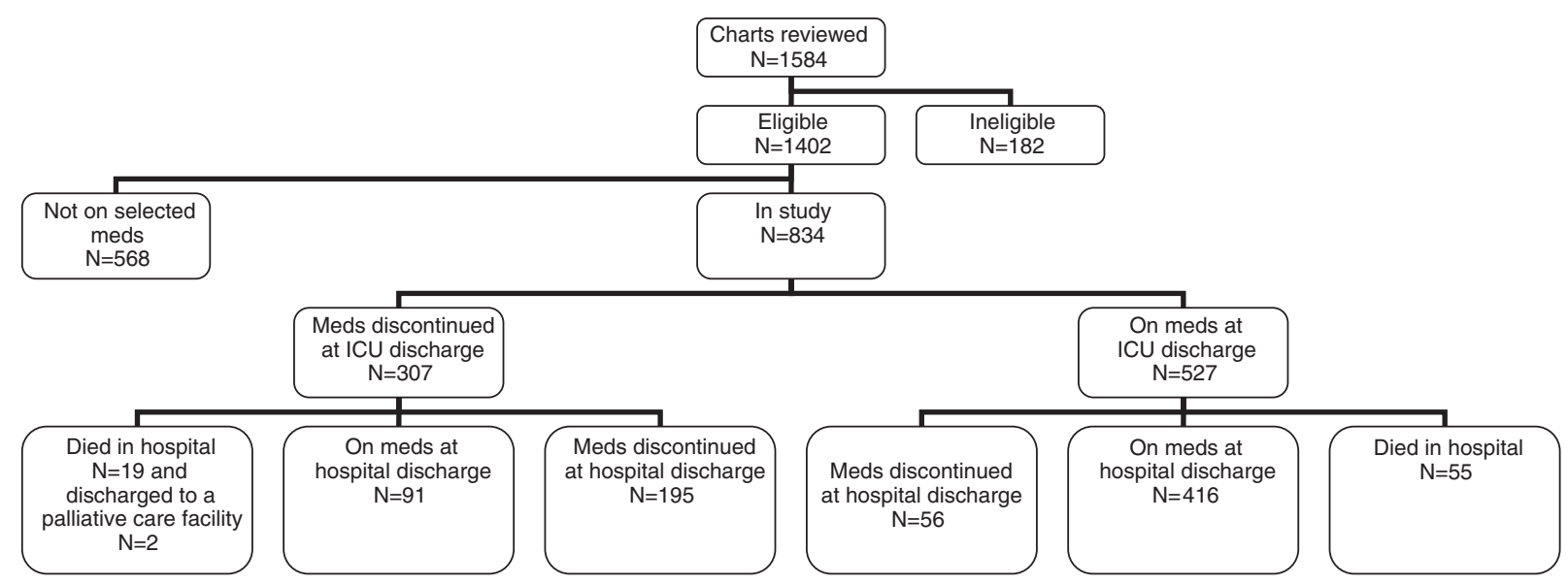

Figure 1. Flowchart of Study Particpants 
Table 1. Demographic Characteristics and Clinical Data

\begin{tabular}{|c|c|c|c|}
\hline & $\begin{array}{l}\text { Academic Hospital } \\
\qquad(N=670)\end{array}$ & $\begin{array}{l}\text { Community Hospitals } \\
\qquad(N=732)\end{array}$ & $\begin{array}{c}\text { Total } \\
(N=1,402)\end{array}$ \\
\hline Median age (interquartile range) & 64 (52 to 75$)$ & 66 (51 to 77$)$ & 65 (50 to 76$)$ \\
\hline Female, $N(\%)$ & $269(40 \%)$ & $327(45 \%)$ & $596(43 \%)$ \\
\hline Married, $N(\%)$ & $242(36 \%)$ & $392(54 \%)$ & $634(45 \%)$ \\
\hline Nursing home resident, $N(\%)$ & $29(4 \%)$ & $28(4 \%)$ & $57(4 \%)$ \\
\hline Emergency contact listed, $N(\%)$ & $582(87 \%)$ & $680(93 \%)$ & $1,262(90 \%)$ \\
\hline Primary care provider listed, $N(\%)$ & $539(80 \%)$ & $634(87 \%)$ & $1,173(84 \%)$ \\
\hline Admitted via emergency department, $N(\%)$ & $329(49 \%)$ & $531(73 \%)$ & $860(61 \%)$ \\
\hline Median number of medications on admission (interquartile range) & 5 (2 to 7$)$ & $4(1$ to 6$)$ & 4 (2 to 7$)$ \\
\hline Direct admission to ICU, $N(\%)$ & $140(21 \%)$ & 359 (49\%) & $499(36 \%)$ \\
\hline Same ward/ICU attending, $N(\%)$ & 0 & $134(18 \%)$ & $135(10 \%)$ \\
\hline Intubated in ICU, $N(\%)$ & $266(40 \%)$ & $182(25 \%)$ & $448(32 \%)$ \\
\hline Medical diagnosis on ICU admission, $N(\%)$ & $240(36 \%)$ & $435(59 \%)$ & $675(48 \%)$ \\
\hline Median length of stay in ICU (interquartile range), d & 2 (2 to 3$)$ & $3(2$ to 5$)$ & $3(2$ to 5$)$ \\
\hline Median length of stay in hospital (interquartile range), $d$ & $11(7$ to 24$)$ & 10 (6 to 18$)$ & $10(6$ to 21$)$ \\
\hline
\end{tabular}

ICU, intensive care unit.

hospital without note of selected, previously prescribed chronic medications. The majority of patients who had their medication discontinued on discharge from hospital also had their medication discontinued on discharge from the ICU. We found that patients from the academic hospital and those with medical diagnoses had a lower risk for chronic medication discontinuation.

The $20 \%$ to $25 \%$ rate of unintentional discontinuation in 5 of the 6 medication groups suggests a consistent effect. The selected drugs represent a diverse group of chronic medications with evidence-based indications and limited contraindications. $^{14-20}$ These findings are of particular importance because the medication discontinuation occurred in a patient group already prescribed the drug before hospital admission. These errors of omission constitute a problem in care, and may place these patients at increased risk for avoidable morbidity. The higher rate of discontinuation in the allopurinol group may represent drug-specific issues regarding its perceived value as well as unrecognized deliberate discontinuation.

We also observed that patients with medical diagnoses had a decreased risk for unintentional medication discontinuation at hosptial discharge. Patients with medical diagnoses may have better documentation of their admission medications because they may be related to the presenting illness. Many surgical patients are admitted to the ICU on an emergent and unplanned basis as compared with the planned admissions occurring with elective surgical patients. The focus on initial stabilization of the patient and their deteriorating sur- gical status may be an additional distraction to proper documentation of chronic medication regimens. There may also be poorer documentation of discharge medications on surgical wards. Also, we found a decreased risk for medication discontinuation in the academic hospital studied. Possible explanations for this finding could include the effect of multiple physicians caring for the patients during coverage, or other process of care differences between community and academic hospitals. As demonstrated in Table 1, there were considerable differences between community and academic hospitals in the proportions admitted via the emergency department, being directly admitted to the ICU, having the same ward/ICU attending, intubated in the ICU, and those having a medical diagnosis on ICU admission. Adjustment for these covariates overcame the initial similarity observed in the proportions of patients having their medication discontinued on hospital discharge. Indeed, the possibility of residual confounding may explain the adjusted result and make us uncertain about the generalizability of this characteristic because of the small number of institutions in our study. Further research is warranted.

Understandably, clinicians focus on acute issues when patients are admitted to the ICU. However, medical errors often relate to gaps in communication, particularly with respect to care transitions. ${ }^{4-8,22-24}$ A patient's discharge from the ICU is a time when longer-term treatment goals are contemplated and usual medications should be resumed or reconsidered particularly for those drugs that were contraindicated during

Table 2. Proportion whose Medications were Discontinued on Discharge from ICU or Hospital ${ }^{*}$

\begin{tabular}{llr}
\hline \hline \multicolumn{1}{c}{ Medication } & Proportion Discontinued on ICU Discharge & Proportion Discontinued on Hospital Discharge \\
\hline Acid-suppressing drugs ${ }^{\dagger}$ & $26 \%(80 / 310)$ & $25 \%(72 / 287)$ \\
Allopurinol & $52 \%(28 / 54)$ & $50 \%(25 / 50)$ \\
Antiplatelet/anticoagulants & $23 \%(92 / 405)$ \\
L-thyroxine preparations & $27 \%(119 / 448)$ & $21 \%(23 / 110)$ \\
Non-prn Inhalers & $16 \%(27 / 170)$ \\
Statins & $19 \%(45 / 243)$ & $20 \%(43 / 219)$ \\
Overall proportion per patient & $30 \%(87 / 289)$ & $21 \%(58 / 271)$ \\
\hline
\end{tabular}

*Some patients were on more than 1 of the selected medications.

${ }^{\dagger}$ Acid-suppressing drugs $=\mathrm{H} 2$ antagonists and proton pump inhibitors.

${ }^{\ddagger}$ Antiplatelets $/$ anticoagulants $=$ aspirin, clopidogrel, ticlopidine, warfarin.

${ }^{\S}$ Non-prn inhalers $=$ anticholinergic, $\beta$-agonist, or steroid inhalers. 
Table 3. Results of Multivariable Logistic Regression Model for Medication Discontinuation at Hospital Discharge

\begin{tabular}{|c|c|c|}
\hline & $\begin{array}{l}\text { Unadjusted Odds Ratio } \\
\text { (95\% Confidence Interval) }\end{array}$ & $\begin{array}{c}\text { Adjusted Odds Ratio } \\
\text { (95\% Confidence Interval) }\end{array}$ \\
\hline Age & $1.0(0.99$ to 1.0$)$ & $0.99(0.98$ to 1.0$)$ \\
\hline Female sex & $0.78(0.57$ to 1.1$)$ & $0.75(0.55$ to 1.0$)$ \\
\hline Academic hospital & $0.92(0.68$ to 1.3$)$ & $0.70(0.49 \text { to } 1.0)^{\dagger}$ \\
\hline Admitted via emergency department & $0.92(0.68$ to 1.3$)$ & $1.4(0.93$ to 2.2$)$ \\
\hline Number of medications on hospital admission & $1.0(0.96$ to 1.1$)$ & $1.0(0.97$ to 1.1$)$ \\
\hline Same ward/ICU attending & $0.56(0.31$ to 1.0$)$ & $0.60(0.32$ to 1.1$)$ \\
\hline Intubated in ICU & $0.93(0.67$ to 1.3$)$ & $0.95(0.65$ to 1.4$)$ \\
\hline Medical diagnosis on ICU admission & $0.65(0.47 \text { to } 0.88)^{\dagger}$ & $0.48(0.31 \text { to } 0.75)^{\dagger}$ \\
\hline Length of stay in ICU (d) & $0.99(0.97$ to 1.0$)$ & $0.99(0.97$ to 1.0$)$ \\
\hline Length of stay in hospital (d) & $1.0(0.99$ to 1.0$)$ & $1.0(0.99$ to 1.0$)$ \\
\hline
\end{tabular}

ICU, intensive care unit.

*Adjusted for all other covariates listed.

${ }^{\dagger} \mathrm{P}<.05$.

a patient's initial instability. Any omission of important chronic medications may persist as clinicians tend to focus on the last transition point when assuming care. ${ }^{4,25}$ Our study underscores the notion that failure to restart these chronic medications on transition of care may place patients at greater risk of unintentional medication discontinuation on discharge from hospital. ${ }^{11-13,26}$ This emphasizes the importance of better communication for the reconciliation of preadmission and discharge medications at every transition of care..$^{9,27-29}$ This strategy can be implemented through methods ranging in complexity from customized computerized systems to simple preprinted forms but its success relies on the inclusion of hospital and community pharmacists, specialty and primary care physicians, nurses, and the patients themselves. ${ }^{9,30,31}$ However, the impact of this type of campaign has not been determined in a large-scale and rigorous manner. Nevertheless, any method to address the issue of medication omission is rooted in better communication.

Few studies have examined continuity of medications in hospitalized patients, particularly those discharged from the ICU. Most have focused on inaccuracies in medication lists during the admission and discharge processes for medicine ward patients. ${ }^{13,24,28,32-35}$ We did not find that the number of medications prescribed to patients was an independent predictor of medication discontinuation, although it has been associated with medication errors and discrepancies in previous work. ${ }^{24}$ Variations in study methodology, patient populations, and outcome definitions may contribute to these differences. More importantly, however, is our finding that discharge from the ICU without note of previously prescribed chronic medications substantially increases the risk of discharge from hospital without note of the same previously prescribed chronic medications.

Our study has limitations that merit consideration. Firstly, we were dependent upon adequate hospital chart documentation for our data. However, we carefully reviewed the clinical context to determine whether deliberate medication discontinuation may have occurred. Also, we relied on the list of admission medications from various sources to determine medication continuity. Poor or inaccurate documentation on admission and discharge may have overestimated our findings by including patients erroneously listed as taking 1 of the selected medications on admission or counting patients actually prescribed medication on discharge without record. Still, inadequate documentation before ICU admission might have resulted in an underestimate of the true effect. Secondly, we did not review the reason for the original clinical prescriptions. Of course, some of the medications may not have been clearly indicated before hospital admission. In our study, it is possible that such medications may have been discontinued owing to a lack of indication. However, these thoughts were rarely documented in the hospital records. Furthermore, the ICU is usually not the appropriate setting to decide upon the indications for long-term medication prescriptions. Thirdly, our study only involved 3 centers. Although 1 of our findings identified the academic center as having a higher risk of unintentional medication discontinuation, this might be attributable to many factors unduly influenced by practice at 1 site. Finally, our implicit assumption was that patients not prescribed medication at hospital discharge did not continue their medication in the community. Follow-up and outcome assessment are subjects for further study to gauge the importance of this phenomenon.

Gaps in the continuity of health care are an area of vulnerability for patient safety. ${ }^{4,36}$ We found that patients discharged from the ICU often leave hospital without note of their previously prescribed chronic medications. Our study is novel in its focus on the ICU, transfers of care, the examination of errors of omission, and particularly the unintentional discontinuation of chronic medications with demonstrated effectiveness. It is likely that these findings extend to other types of medications as well as the broader context of care transitions after hospitalization. Careful review of medication lists at ICU discharge and better interdisciplinary communcation strategies could avoid potential adverse outcomes related to unintentional discontinuation of chronic medications at hospital discharge. Successes in the acute resuscitation and management of patients in the ICU should translate into similar successes in long-term disease management with chronic medications when these patients leave the hospital.

We would like to thank Drs. Damon Scales, Sandy Finkelstein, and Mark Varkul for their exceptional assistance with the project. Dr. Bell is the recipient of a Phase 2 Clinician-Scientist Award from the Canadian Institutes of Health Research. The funding agencies had no role in the design and conduct of the study; collection, management, analysis, or interpretation of the data; or preparation, review, or approval of the manuscript. The corresponding author had full access to all of the data in the study and takes responsibility for the integrity of the data and the accuracy of the data analysis. 


\section{REFERENCES}

1. Haynes RB, Taylor DW, Sackett DL. Compliance in Health Care. Baltimore, MD: Johns Hopkins Press; 1979.

2. McDonald HP, Garg AX, Haynes RB. Interventions to enhance patient adherence to medication prescriptions: scientific review. JAMA. 2002;288:2868-79.

3. Haynes RB, McDonald HP, Garg AX. Helping patients follow prescribed treatment: clinical applications. JAMA. 2002;288:2880-3.

4. Cook RI, Render M, Woods DD. Gaps in the continuity of care and progress on patient safety. BMJ. 2000;320:791-4.

5. Coleman EA, Berenson RA. Lost in transition: challenges and opportunities for improving the quality of transitional care. Ann Intern Med. 2004;141:533-6.

6. Lofgren RP, Gottlieb D, Williams RA, Rich EC. Post-call transfer of resident responsibility: its effect on patient care. J Gen Intern Med. 1990; 5:501-5.

7. Gottlieb DJ, Parenti CM, Peterson CA, Lofgren RP. Effect of a change in house staff work schedule on resource utilization and patient care. Arch Intern Med. 1991;151:2065-70.

8. Petersen LA, Brennan TA, O'Neil AC, Cook EF, Lee TH. Does housestaff discontinuity of care increase the risk for preventable adverse events? Ann Intern Med. 1994;121:866-72.

9. Pronovost $\mathbf{P}$, Weast $\mathbf{B}$, Schwarz $\mathbf{M}$, et al. Medication reconciliation: a practical tool to reduce the risk of medication errors. J Crit Care. 2003; 18:201-5.

10. Moore C, Wisnivesky J, Williams S, McGinn T. Medical errors related to discontinuity of care from an inpatient to an outpatient setting. J Gen Intern Med. 2003;18:646-51.

11. Heeschen C, Hamm CW, Laufs U, Snapinn S, Bohm M, White HD. Withdrawal of statins increases event rates in patients with acute coronary syndromes. Circulation. 2002;105:1446-52.

12. Graves T, Hanlon JT, Schmader KE, et al. Adverse events after discontinuing medications in elderly outpatients. Arch Intern Med. 1997;157: 2205-10.

13. Boockvar K, Fishman E, Kyriacou CK, Monias A, Gavi S, Cortes T. Adverse events due to discontinuations in drug use and dose changes in patients transferred between acute and long-term care facilities. Arch Intern Med. 2004; 164:545-50.

14. Fodor JG, Frohlich JJ, Genest JJ, McPherson PR. Recommendations for the management and treatment of dyslipidemia. Report of the working group on hypercholesterolemia and other dyslipidemias. Can Med Assoc J. 2000; 162:1441-7.

15. Green CJ, Hadorn DC, Bassett K, Kazanjian A. Anticoagulation in chronic nonvalvular atrial fibrillation: a critical appraisal and meta-analysis. Can J Cardiol. 1997;13:811-5.

16. Harrington RA, Becker RC, Ezekowitz M, et al. Antithrombotic therapy for coronary artery disease: the Seventh ACCP Conference on Antithrombotic and Thrombolytic Therapy. Chest. 2004;126(3 Suppl):513S$48 \mathrm{~S}$.

17. Singer PA, Cooper DS, Levy EG, et al. Treatment guidelines for patients with hyperthyroidism and hypothyroidism. Standards of care committee, American Thyroid Association. JAMA. 1995;273:808-12.

\section{Supplementary Material}

The following supplementary material is available for this article online at www.blackwell-synergy.com

Appendix 1.
18. O'Donnell DE, Aaron S, Bourbeau J, et al. Canadian Thoracic Society recommendations for management of chronic obstructive pulmonary disease-2003. Can Respir J. 2003;10(Suppl A):11A-65A.

19. DeVault KR, Castell DO. Updated guidelines for the diagnosis and treatment of gastroesophageal reflux disease. Am J Gastroenterol. 2005; 100:190-200

20. Terkeltaub RA. Clinical practice. Gout. N Engl J Med. 2003;349:164755.

21. Landis JR, Koch GG. The measurement of observer agreement for categorical data. Biometrics. 1977;33:159-74.

22. Kohn LT, Corrigan JM, Donaldson MS, eds. To Err is Human: Building a Safer Health System. Washington, DC: National Academy of Sciences; 2000.

23. Weingart SN, Wilson RM, Gibberd RW, Harrison B. Epidemiology of medical error. BMJ. 2000;320:774-7.

24. Coleman EA, Smith JD, Raha D, Min SJ. Posthospital medication discrepancies: prevalence and contributing factors. Arch Intern Med. 2005; 165: 1842-7.

25. Gandhi TK. Fumbled handoffs: one dropped ball after another. Ann Intern Med. 2005; 142:352-8.

26. Forster AJ, Murff HJ, Peterson JF, Gandhi TK, Bates DW. The incidence and severity of adverse events affecting patients after discharge from the hospital. Ann Intern Med. 2003;138:161-7.

27. Bajcar J, Farrell B, Foisy M. Patient-centered transfer of medication related information. Can Pharm J. 1997;130:27-30.

28. Cornish PL, Knowles SR, Marchesano R, et al. Unintended medication discrepancies at the time of hospital admission. Arch Intern Med. 2005; 165:424-9.

29. Coleman EA, Mahoney E, Parry C. Assessing the quality of preparation for posthospital care from the patient's perspective: the care transitions measure. Med Care. 2005;43:246-55.

30. Institute for Health Improvement. Getting Started Kit: Prevent Adverse Drug Events (Medication Reconciliation). Institute for Health Improvement. 2005. Available at: http://www.ihi.org/NR/rdonlyres/47D5AE1COB29-4A59-8D58-BABF8F4E829F/0/ADEHowtoGuideFINAL5_25.pdf. Accessed January 23, 2006

31. Kaushal R, Barker KN, Bates DW. How can information technology improve patient safety and reduce medication errors in children's health care? Arch Pediatr Adolesc Med. 2001;155:1002-7.

32. Kellaway GS, McCrae E. Non-compliance and errors of drug administration in patients discharged from acute medical wards. $\mathrm{N} \mathrm{Z} \mathrm{Med} \mathrm{J.}$ 1975;81:508-12.

33. Schumock GT, Guenette AJ, Keys TV, Hutchinson RA. Prescribing errors for patients about to be discharged from a university teaching hospital. Am J Hosp Pharm. 1994;51:2288-90.

34. Abrams J, Andrews K. The influence of hospital admission on long-term medication of elderly patients. J Roy Coll Physicians London. 1984;18: 225-7.

35. Beers MH, Dang J, Hasegawa J, Tamai IY. Influence of hospitalization on drug therapy in the elderly. J Am Geriatr Soc. 1989;37: 679-83.

36. Brook RH, Appel FA, Avery C, Orman M, Stevenson RL. Effectiveness of inpatient follow-up care. N Engl J Med. 1971;285:1509-14. 